\title{
Determination of Temperament with the help of Hair Thickness and Colour
}

Mohd Nasir*

Associate Professor, Deoband Unani Medical College and Research Centre, Deoband, (Saharanpur), India

\section{Article Info}

\author{
*Corresponding author: \\ Mohd Nasir \\ Deoband Unani Medical College and \\ Research Centre \\ Deoband, (Saharanpur) \\ India \\ E-mail: nasir7737@rediffmail.com
}

\section{Received: February 27, 2019 \\ Accepted: March 8, 2019 \\ Published: March 19, 2019}

Citation: Nasir M. Determination of Temperament with the help of Hair Thickness and Colour. Int J Tradit Med Appl. 2019; 1(1): 18-21.

doi: 10.18689/ijtma-1000104

Copyright: (c) 2019 The Author(s). This work is licensed under a Creative Commons Attribution 4.0 International License, which permits unrestricted use, distribution, and reproduction in any medium, provided the original work is properly cited.

Published by Madridge Publishers

\begin{abstract}
Mizaj (temperament) is one of the basic and fundamental concepts of Unani system of medicine. Every individual has its own unique temperament. Hair is the driest organ of the body. The climate of different countries differ and their inhabitants are affected by it, hence it has clear that temperament of people of different places cannot be the same, just as the complexion of people of different places differ, so does their hair. In fact variety of hair is an obvious evidence of variety of temperament.

In this study hair thickness and hair colour were studied in 70 volunteers of different temperament. It was found that the volunteers of Safravi mizaj have thick and dark hair, Balghami mizaj volunteers have thin and light hair colour and Damvi mizaj volunteers have hair thickness and colour between Safravi and Balghami mizaj volunteers.
\end{abstract}

Keywords: Temperament; Hair thickness; Hair colour.

\section{Introduction}

The history of medicine dates as far back as the history of man itself, and with changing times medicine also changed its way and gave birth to different medical systems with their own principles and philosophies of treatment. And, one of the oldest systems, which emerged triumphant with changing trends, sticking to its basic principles even today, is undoubtedly Unani System of Medicine. During recent years a spirit of enquiry and research in this system by the medical profession regarding the use of medicines in the treatment of various diseases has developed. Public has also attracted to the system as these medicine are more suited to the habits of the people. Mizaj (Temperament) is one of the unique concepts of Unani System of Medicine, which the physicians of Unani dealt with in detail and defined to the best of their knowledge and holistic approach.

The Great Unani Physicians have described several parameters to diagnose the mizaj of individual. Jalinoos (Galen), Ali Ibn-e-Abbas Majoosi, Zakaria Razi and Ismail Jurjani etc, have described only five parameters which is called "Ajnas-e-Khamsa" while Ibn-e-Sina has described ten parameters known as "Ajnas-e-ashra".

Sha'r (hair) is one of the important amongst the ten determinants of Mizaj. It is the third criteria to determine the mizaj of individuals.

Sha'r (hair) is a body's waste product, which is produced by a kind of waste material of the body which is excreted towards the skin by tabi'at, and having dry temperament [1]. Zakaria Razi also described the Sha'r of the body in fuzlat-e-badan [2].

For the determinantion of mizaj from the Sha'r (hair), following things are seen [3]:

- Fast or slow growth of the hairs.

- Excess or sparseness of the hairs.

- Thickness or thinness of the hairs.

- Straightness or curliness of the hairs and

- Colour of the hair etc [3]. 
Exuberance of hair, their thickness, curliness and darkness indicates heat and dryness and being otherwise, indicates cold and moistness [4]. Hair is the driest in all organs of the body $[5,6]$. The climate of different countries differ and their inhabitants are affected by it, hence it is clear that temperament of people of different places cannot be the same, just as the colour of people of different places differ, so does their hair. In fact variety of hair is obvious evidence. According to the Unani System of Medicine, Black hair denotes heat; reddish brown hair indicates cold; Yellow red and red hair show equability of temperament. Grayness of hair either shows moisture and cold as in old age or it shows much dryness as it happens with the plants when their darkness turns into whiteness owing to their dryness. This happens also in man after desiccating diseases. According to Aristotle, the cause of grayness of hair is that the substance changes into the colour of phlegm. According to Galen, it is moistness which necessarily accompanies the nutriment coming to the hair when the nutriment is cold and slow in motion while it is penetrating into pores. If we consider both views, we will really find them quite similar because the white colour of both phlegm and moisty matter results from the same cause and this pertains to physis. After this, it must be kept in view that countries and climates also affect the hair. Thus one should not expect to find yellow red hair in Negroes in order to infer from it the equability of their particular temperament; similarly, one should not expect to find black hair in slaves in order to infer it from the dryness of their particular temperament. Age, too has an influence in the matter of the hair. Thus the youth are like the inhabitants of southerly countries, the children are like the inhabitants of the northerly countries and the middle aged are like the inhabitants of central region. Abundance of hair in a child indicates that its temperament will change to atrabilious when it grows up; and in the elderly person it shows that his temperament is atrabilious at present [7].

An attempt is made in this study to giving scientific orientation to our Unani literature.

\section{Materials and Methods}

This study was carried out in the Post Graduate Department of Kulliyat at Ajmal Khan Tibbiya College, Aligarh Muslim University, Aligarh. Seventy (70) healthy volunteers of either sex having Phlegmatic (Balghami), Bilious (Safravi) or Sanguine (Damvi) temperament were selected for the study. Melancholic (Saudavi) volunteers were not included in the study because of lower number.

\section{Inclusion criteria}

Phlegmatic, Bilious and Sanguine healthy volunteers in the age group of 18-30 years and without any apparent morbidity and no history of any disease were included in the study.

\section{Exclusion criteria}

Volunteers having history of using dyes and colour on the scalp hairs, skin disease, hair disease and history of medication were excluded from this study.

\section{Determination of temperament}

The assessment of Mizaj (temperament) of the volunteers were made on the basis of a self designed Performa (questionnaire) prepared in the light of criteria described in classical Unani literature i.e., ten determinants i.e., Ajnas-eAshra.

\section{Categorization of volunteers}

The selected volunteers were divided into three groups according to their temperament.

Group A : Phlegmatic temperament (Balghami)

Group B : Bilious temperament (Safravi)

Group C : Sanguine temperament (Damvi)

After determination of the temperament of healthy volunteers, hair samples were collected.

First advice the volunteer to comb their hair and then collect the fallen hair from the comb and sheet spread for the purpose. The hair is collected in a small packet. The collected hair is loosely placed on the surface of scanner and then scans the hair with the help of computer scan software and JPEG image is formed. From this JPEG image we assess the colour and shape of the hair. The thickness of hair is measured by the Digital Vernier Caliper.

\section{Measurement of hair thickness}

The hair sample was placed between the external jaws and they were carefully brought together. The locking screw is tightened so that the jaws do not more apart. The digital display can then be read. The thickness can be read by inch/ $\mathrm{mm}$ button. The thickness was measured in millimeter $(\mathrm{mm})$.

\section{Colour of the hair}

First of all hair sample was scan with the help of computer scan software and JPEG image is formed. From this JPEG image we assess the colour of hair. The colour of hair was assessed with the help of photoshop software by RGB colour scale. The RGB colour model is an additive colour model in which red, green and blue light are added together in various ways to reproduce a broad array of colours. The name of the model comes from the initials of the three additive primary colours, red, green and blue. The main purpose of the RGB colour model is for the sensing, representation and display of images in electronic systems such as computers, though it has also been used in conventional photography. Colorimetry, computer graphics and video signal transmission standards have given birth to many colours spaces with different properties. A variety of them have been applied to the problem of hair colour modeling, the RGB colour scale is most popular and widely used scale for this purpose. This RGB model specifies the intensity of red, green and blue on a scale of 0 to 255 , with 0 (zero) indicating the minimum intensity. Thus any value nearer to 0 will be more dark.

The setting of these three colours were converted to a single integer value by using this formula [8].

RGB value $=$ Red $+($ Green $\times 256)+($ Blue $\times 256 \times 256)$ 


\section{Observation and Results}

The aim of this study was to rule out whether any correlation exists between thickness of hair \& colour of hair and temperament or not.

Data obtained in this study were statistically evaluated.

Out of seventy (70) volunteers, 16 Balghami, 21 Safravi and 33 were Damvi temperament and their percentage was $22.9 \%, 30 \%$ and $47.1 \%$ respectively (Figure 1 ).

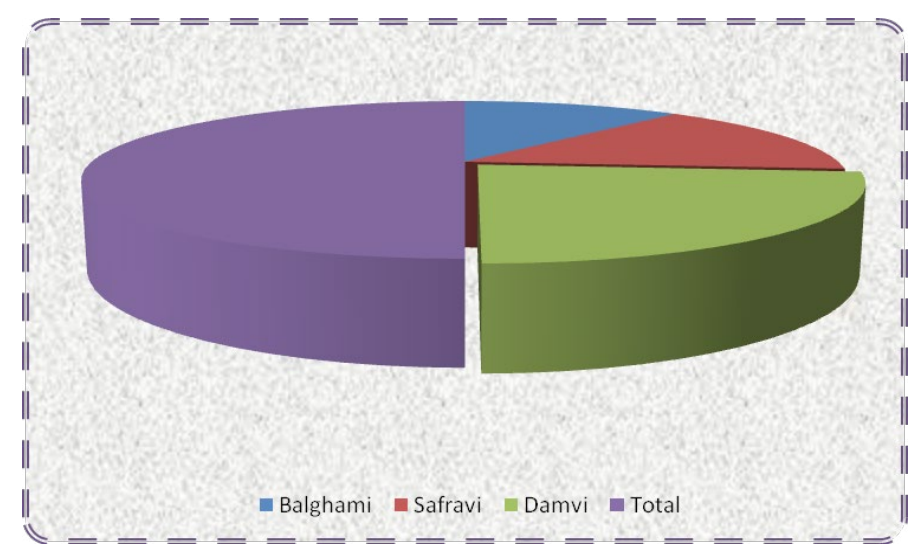

Figure 1. Showing distribution of volunteers according to temperaments.

Out of 70 volunteers, 47 were male and 23 were female and their percentage was $67.1 \%$ and $32.9 \%$ respectively. Among 47 male volunteers, 10 (14.3\%) belonged to Balghami temperament, 15 (21.4\%) were Safravi temperament and 22 (31.4\%) were found to be Damvi temperament (Figure 2). Out of 23 female volunteers 6 (8.6\%) were Balghami, 6 (8.6\%) were Safravi and 11 (15.7\%) were of Damvi temperament.

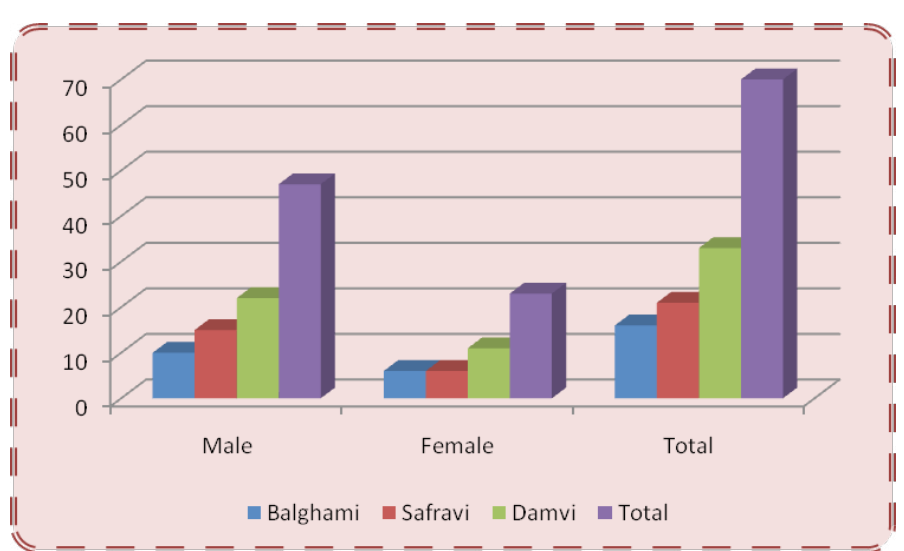

Figure 2. Showing distribution of volunteers according to sex.

In this study, volunteers were in age group of 18-30 years. In age group 18-22 year, three (3) volunteers were Balghami, two (2) were Safravi and nine (9) were Damvi. In age group 23-26 years, six (6) were Balghami, seven (7) were Safravi and fourteen (14) were Damvi. In age group 27-30 years, seven (7) were Balghami, twelve (12) were Safravi and ten (10) were Damvi (Figure 3).

In Balghami maximum volunteers found in 27-30 years age group. In Safravi maximum volunteers also found in 27-30 years age group. In Damvi maximum volunteers found in 23-26 years age group. If we see overall in all the three temperament then maximum volunteers found in 27-30 years age group and minimum volunteers found in $18-22$ years of age group.

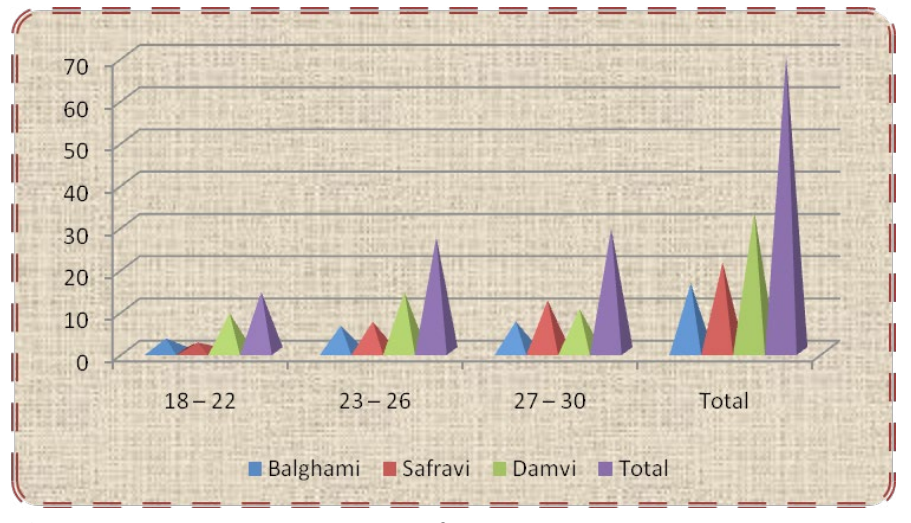

Figure 3. Showing distribution of volunteers according to their age.

Hair thickness of volunteers was calculated. Mean value of Balghami volunteers was less as compared to Safravi volunteers. In this present study we have observed that Safravi volunteers have thick hair, Balghami volunteers have thin hair and Damvi volunteers thickness are between Safravi and Balghami volunteers (Table 1). Thickness of hair was expressed in millimeters $(\mathrm{mm})$.

Table 1. Showing thickness of hairs of volunteers expressed as Mean \pm S.D.

\begin{tabular}{|l|c|c|}
\hline Temperament & No. of Volunteers & Mean \pm S.D. \\
\hline Balghami & 16 & $0.051 \pm 0.013$ \\
\hline Safravi & 21 & $0.062 \pm 0.014$ \\
\hline Damvi & 33 & $0.057 \pm 0.016$ \\
\hline
\end{tabular}

The present study reveals that Balghami and Safravi temperament $(t=2.4, p<0.05)$ results are significant (Table 2$)$. In Balghami and Damvi temperament and in Safravi and Damvi temperament results are insignificant.

Table 2. Showing significance of thickness of hair in between different temperament.

\begin{tabular}{|l|c|}
\hline Temperament & Significance \\
\hline Balghami+Safravi & $\mathrm{t}=2.4, \mathrm{p}<0.05$ \\
\hline Balghami+Damvi & $\mathrm{t}=1.3$ \\
\hline Safravi+Damvi & $\mathrm{t}=1.2$ \\
\hline
\end{tabular}

Colour of hair of volunteers were evaluated. Mean value of Balghami volunteers are higher than Safravi and Damvi, it shows that Balghami volunteers have less dark (light colour) hair as compared to Safravi and Damvi (Table 3). Safravi volunteers have darker hair colour. The value of Damvi volunteers lies between Safravi and Balghami.

Table 3. Showing colours of hairs of volunteers expressed as Mean \pm S.D.

\begin{tabular}{|l|c|c|}
\hline Temperament & No. of Volunteers & Mean \pm S.D. \\
\hline Balghami & 16 & $9640966 \pm 1018505$ \\
\hline Safravi & 21 & $5009965 \pm 1725573$ \\
\hline Damvi & 33 & $7169887 \pm 1997871$ \\
\hline
\end{tabular}

The present study also reveals that the correlation between Balghami and Safravi temperament $(t=9.6, P<0.001)$ were significant. In Balghami and Damvi temperament ( $\mathrm{t}=4.7$, $\mathrm{P}<0.001)$ values are also significant and in Safravi and Damvi temperament $(\mathrm{t}=4.1, \mathrm{P}<.001)$ results are also Significant. So we found that between these three temperaments results are hundred percent significant (Table 4).

The present study of seventy (70) volunteers, we observed that a relation can be established in characteristics of hairs 
and temperament. The Safravi mizaj volunteers have thick and darker hairs as compared to Balghami mizaj volunteers. The Damvi mizaj volunteers hair thickness and colour lies between Safravi and Balghami.

Table 4. Showing significance of colour of hair in between temperaments.

\begin{tabular}{|l|c|}
\hline Temperament & Significance \\
\hline Balghami+Safravi & $\mathrm{t}=9.6, \mathrm{P}<0.001$ \\
\hline Safravi+Damvi & $\mathrm{t}=4.7, \mathrm{P}<0.001$ \\
\hline Safravi+Damvi & $\mathrm{t}=4.1, \mathrm{P}<0.001$ \\
\hline
\end{tabular}

\section{Discussion}

Thickness of hair was maximum in Safravi temperaments and least in Balghami temperament. Our results confirm this claim of Unani Medicine. We found maximum thickness in Safravi mizaj volunteers with mean thickness $0.062 \pm 0.014$ $\mathrm{mm}$. The difference in thickness between Balghami and Safravi volunteers was found statistically significant $(p<0.05)$.

In our study we found the value of Safravi volunteers (5009965 \pm 1725573 ) lesser than other groups, which mean Safravi have darker hair as compared to other groups and this difference was statistically significant $(p<0.001)$. This finding is in accordance with the characteristics of Safravi temperament as mentioned in Unani literature. Balghami volunteers hair colour has highest RGB value, thus indicating light colour of their hair, which is again in agreement of Unani literature.

Our study has not only validate scientifically Unani claims regarding hairs thickness and colour but it has also provided a value to use it as a parameter for determination of human mizaj.

\section{Main findings}

- The Safravi (Bilious) mizaj volunteers have hair thickness is greater than Balghami (Phlegmatic) and Damvi (Sanguine) mizaj.

- The Safravi (Bilious) mizaj volunteers have dark hair than Balghami (Phlegmatic) and Damvi (Sanguine) mizaj.

- Balghami (Phlegmatic) mizaj volunteers have thin hair than Safravi (Bilious) and Damvi (Sanguine) mizaj.

\section{Strength of study}

Mizaj (Temperament) is one of the unique concepts of Unani System of Medicine, which the physician dealt in detail and defined to the best of their knowledge and holistic approach. Description of mizaj is found in classical Unani literature. The theory of mizaj (temperament) is backbone of Unani system of medicine. In this study we correlate and validate the theory of mizaj to modern concept to pave the way for further research.

\section{Future recommendation}

Further studies are also required to assess variability of different physiological, pathological, biochemical parameters in healthy subjects of different temperaments in relation to hair. In future, more extensive studies in a large sample size with some advance equipment. All four temperament should be included in the study.

\section{Clinical implication}

This study validated the classical theory of mizaj (temperament) and this study will help in diagnosis or determination of temperament of subject with help of scalp hair.

After determination of mizaj we treat the patient according to their temperament and suitable Unani medicines are prescribed.

\section{Conclusion}

From the present sample size of seventy (70) volunteers with above material and method and observation, it may be concluded that:

- The individuals having Safravi (Bilious) temperaments have thick hair and dark hair color.

- Balghami individuals have thin hair and lighter hair colour.

- Damvi individuals hair thickness and colour lies between bilious (Safravi) and phlegmatic (Balghami) volunteers.

- Thus relationship can be established between Mizaj (temperament) and characteristics of hairs (thickness and colour) which validates the claim that Safravi individuals have thick and darker hair colour. Balghami have thin and lighter hair colour and Damvi individuals hair thickness and colour lies between Safravi and Balghami volunteers.

The data obtained so far is provisional and it does encourage further, more extensive studies in a large sample size with some advance equipment.

The theory of temperament is the basic philosphy of Unani medicine. Recent studies have not contradicted in anyway the concept of four Mizaj (temperament). Various branches of medicine notably Genetics, Immunology, Psychosomatic medicine etc. have also begun to support this theory, still a more sound scientific validation of this theory is obligatory for its rational and universal application. The need of hour is to study the concept of temperament at the genetic level. Further studies are also required to assess variability of different physiological, pathological, biochemical parameters in healthy subjects of different temperaments in relation to hairs.

\section{References}

1. Tabri R, Sahal AB. Firdaus-ul-Hikmat Fil Tibb. Urdu translation by Rasheed RA. Hamdard Foundation Press, Karachi. 1981: 153-154.

2. Rhazi BA, Zakaria MB. Kitab-ul- Mansoori. Urdu translation by CCRUM, New Delhi. 1991: 59-62.

3. Ibn-E-Sina B, Abu Ali Hussain A. Al-Qanun Fil-Tibb Part I. Urdu translation by Ghulam Hussain Kintoori, Matba Munshi Naval Kishore, Lucknow, 1303 Hijri. 13: 152-157.

4. Ibn-e-Nafees, Burhanuddin Kirmani Ibn-e-Ooz. Killiyat-e-Nafisi. Volume II, Urdu Translation and Elaboration (Sharah) by Kabiruddin HM, Daftar-Al-Maseeh M, Noor-ul-Umra B. Hyderabad Deccan, 1954: 73-74,266-268,269-272.

5. Kabiruddin M. Ifada-e-Kabir Muffasal. Islamic Bazar, Noor-ul-Umra. Hyderabad. 1947: 21,22,37,81.

6. Qarshi HMd. Mukhtasarul Kulliyat. Tarjuma wa Sharah Mojiz-al-Qanun Daftar Masheerul Atibba wa chasma-e-Zindagi. Lahore. 12.

7. Ibn-E-Sina B, Abu Ali Hussain A. Al Qanoon Fil-Tibb I. English translation of the Critical Arabic text by Department of Islamic Studies. Jamia Hamdard, New Delhi. 1993: 191-193, 195.

8. Microsoft. RGB Color Model. 2010. 